\title{
STUDY OF EFFICACY OF PLATELET RICH PLASMA DRESSING IN MANAGEMENT OF CHRONIC NON- HEALING LEG ULCERS
}

\author{
S. R. Kulkarni1, Aditya Chawla ${ }^{2}$
}

1 Professor and HOD, Department of General Surgery, Krishna Institute of Medical Sciences, Karad, Maharashtra, India.

${ }^{2}$ Resident, Department of General Surgery, Krishna Institute of Medical Sciences, Karad, Maharashtra, India.

\begin{abstract}
BACKGROUND
Diabetic foot ulcers continue to be a significant global issue despite the advances made in the management of diabetes. It causes major foot complications if they are not addressed properly. It needs multidisciplinary approach for its care. While several advancements have taken place in wound care management, platelet rich plasma and stem cell therapy promise to offer a new hope in its management, aiding in cellular and tissue regeneration. The purpose of the present study was to compare Platelet-Rich Plasma versus conventional dressing in the management of diabetic foot ulcers.
\end{abstract}

ABSTRACT

\section{METHODS}

Patients presented with chronic non healing ulcers were recruited in this study. This was a prospective study conducted at Krishna Hospital \& Medical Research Centre, Karad. A total of 50 patients was assigned. They were grouped through computerized randomization into two groups. Control group patients were treated with conventional dressing and study group patients were treated with platelet rich plasma (PRP) dressing and observed for reduction in the wound size in a span of 21 days.

\section{RESULTS}

The study group patients showed higher reduction in wound size of about $43.40 \%$ as against $14.03 \%$ in the control group with $p$ value $<0.001$.

\section{CONCLUSIONS}

Platelet rich plasma dressing significantly increases incidence of wound healing in chronic lower limb ulcers.

HOW TO CITE THIS ARTICLE: Kulkarni SR, Chawla A. Study of efficacy of platelet rich plasma dressing in management of chronic non healing leg ulcers. J. Evolution Med. Dent. Sci. 2019;8(16):1307-1310, DOI: 10.14260/jemds/2019/291

\section{BACKGROUND}

Chronic wounds are characterized by a long inflammatory phase that hinders regenerative wound healing. Chronic wounds in diabetes mellitus (DM) patients are a major health problem. The goal of wound care in chronic ulcers is to increasing healing and decrees lower extremity amputations using standardized protocols for wound care. The standard treatment includes a complete patient and wound assessment, history, physical examination, and other diagnostic test that determine the need for infection control, revascularization, excision and debridement, skin graft/flap ${ }^{1}$

Apart from these conventional methods to facilitate wound healing various new methods are emerging such as cellular therapies which include platelet-rich plasma (PRP). This can have an adjunctive role in a standardized, quality treatment plan. ${ }^{2}$

Platelets release certain growth factors from alpha granules which are located in thrombocyte cell membrane which include platelet derived growth factor (PDGF), epidermal growth factor (EGF), platelet derived angiogenesis factor and platelet factor 4 . These factors act locally on wound and hasten the healing process. ${ }^{3}$

'Financial or Other Competing Interest': None.

Submission 05-03-2019, Peer Review 10-04-2019,

Acceptance 16-04-2019, Published 22-04-2019.

Corresponding Author:

Dr. Aditya Chawla,

Resident,

Department of General Surgery,

Krishna Institute of Medical Sciences,

Karad-415110, Maharashtra, India.

E-mail: researchexpert3@gmail.com

DOI: $10.14260 /$ jemds $/ 2019 / 291$
Platelet extract has been used in many studies and has shown impressive results in healing of chronic non healing ulcers.

Since not all patients can afford commercially available recombinant platelet gel for dressing, platelet extract from the patient's own blood has been used in trials on chronic wound.

Skin ulcers are defined by the loss of tissue that includes the epidermis and the dermis, at times affecting the adipose tissue and the muscle fascia. Since not all patients can afford commercially available recombinant platelet gel for dressing, platelet extract from the patient's own blood/allogenic platelet concentrate available has been used in trials on chronic wounds. ${ }^{4}$

The purpose of this study is to evaluate how autologous platelet-rich plasma (PRP) affects initial wound healing trajectories of chronic, non-healing wounds in a hospital care setting.

Hence, this study intends to demonstrate the therapeutic role of autologous platelet rich plasma in healing of chronic non-healing ulcers.

\section{METHODS}

Source of Patients who are suffering from chronic nonhealing ulcers and are admitted as inpatients as well as referred from other Departments to the Department of General Surgery, Krishna Hospital \& Research Center, Karad.

\section{Method of Collection of Data}

The study was designed as a prospective, randomizedcontrolled clinical study. Patients were randomly assigned to two groups, about 100 patients were assessed for eligibility of which about 50 where excluded due to not meeting 
inclusion criteria and not willing for participation. Those patients who met the inclusion criteria were explained the entire treatment and follow-up procedure by the study investigator, and only after obtaining voluntary written consent from the patients for the treatment procedure, they were treated with PRP and normal conventional dressing. Their follow-up data was collected. They were randomized using computer generated random numbers and allocated into two groups, Group A and Group B as follows.

\section{Group A}

Cases A (Experimental group, $\mathrm{n}=25$ )

\section{Group B}

$B$ (Control group, $n=25$ ).

Detailed history was taken in all cases regarding the duration, mode of onset, progression, and associated symptoms. Also, the etiological factor responsible was elicited in the history.

Ulcer examination was done in all these patients and wound was assessed of its characteristics and photographed. Ulcer was assessed by the investigator at the beginning of the study and at every dressing and photographed for follow up.

Size of the wound was assessed by placing a meter scale from the edges of the wound in their longest dimensions.

Sample size was taken based on the conveniences of the study.

\section{Statistical Method}

Statistical Methods Results on continuous measurements are presented on Mean \pm SD (Min-Max) and results on categorical measurements are presented in Number (\%). Significance is assessed at $5 \%$ level of significance. Student $t$ test has been used to find the significance of study parameters on continuous scale between two groups (Inter group analysis) on metric parameters.

\section{Statistical Software}

The Statistical software namely SPSS 15.0 was used for the analysis of the data and Microsoft word and Excel have been used to generate tables, ETC Results.

\section{RESULTS}

\begin{tabular}{|c|c|c|c|c|}
\hline \multirow{2}{*}{ Age } & \multicolumn{2}{|c|}{ Study group } & Control Group \\
\cline { 2 - 5 } & Number & $\mathbf{\%}$ & Number & \% \\
\hline Less than 30 & 1 & 4 & 1 & 4 \\
\hline $31-40$ & 4 & 16 & 4 & 16 \\
\hline $41-50$ & 7 & 28 & 8 & 32 \\
\hline $51-60$ & 9 & 36 & 10 & 40 \\
\hline $61-70$ & 1 & 4 & 0 & 0.0 \\
\hline $71-80$ & 3 & 12 & 2 & 8 \\
\hline Total & $\mathbf{2 5}$ & $\mathbf{1 0 0}$ & $\mathbf{2 5}$ & $\mathbf{1 0 0 . 0}$ \\
\hline Mean \pm SD & $51.78 \pm 12.29$ & $50.48 \pm 11.58$ \\
\hline \multicolumn{5}{|c|}{ Table 1. Age Distribution } \\
\hline The mean age in the study group was 51.78 years and in \\
control group was 50.48 years. Samples are age matched with \\
\multicolumn{5}{|c|}{ P=0.713 } \\
\hline
\end{tabular}

\begin{tabular}{|c|c|c|c|c|}
\hline \multirow{2}{*}{ Gender } & \multicolumn{2}{|c|}{ Study Group } & \multicolumn{2}{c|}{ Control Group } \\
\cline { 2 - 5 } & Number & Percentage & Number & Percentage \\
\hline Female & 11 & 44 & 9 & 36 \\
\hline Male & 14 & 56 & 16 & 64 \\
\hline Total & $\mathbf{2 5}$ & $\mathbf{1 0 0 . 0}$ & $\mathbf{2 5}$ & $\mathbf{1 0 0 . 0}$ \\
\hline \multicolumn{4}{|c|}{ Table 2. Sex Distribution } \\
\hline
\end{tabular}

Incidence of chronic lower limb ulcers were more in males in both the groups as compared to females.

\begin{tabular}{|c|c|c|c|c|}
\hline \multirow{2}{*}{$\begin{array}{c}\text { Onset of } \\
\text { Ulcers }\end{array}$} & Study Group & \multicolumn{2}{c|}{ Control Group } \\
\cline { 2 - 5 } & Number & Percentage & Number & Percentage \\
\hline Traumatic & 15 & 60 & 16 & 64 \\
\hline Spontaneous & 10 & 40 & 9 & 36 \\
\hline Total & $\mathbf{2 5}$ & $\mathbf{1 0 0 . 0}$ & $\mathbf{2 5}$ & $\mathbf{1 0 0 . 0}$ \\
\hline \multicolumn{5}{|c|}{ Table 3. Onset } \\
\hline
\end{tabular}

15 patients in the study group and 16 cases in control group presented with traumatic ulcers. Which showed that prevalence of traumatic ulcers was more in comparison with others.

\begin{tabular}{|c|c|c|c|}
\hline & Study Group & Control Group & p Value \\
\hline Initial Area & $1328.5 \pm 128.68$ & $1338.08 \pm 131.54$ & 0.805 \\
\hline Final Area & $749.9 \pm 99.97$ & $1149.84 \pm 114.74$ & $<0.001^{* *}$ \\
\hline CA=IA-FA & $579 \pm 63.55$ & $214.39 \pm 148.20$ & $<0.001^{* *}$ \\
\hline \multicolumn{4}{|c|}{ Table 4. Comparison of Initial Area and Final Area } \\
\hline
\end{tabular}

\begin{tabular}{|c|c|c|c|c|}
\hline \multirow{2}{*}{$\begin{array}{c}\text { \% Area of } \\
\text { Reduction }\end{array}$} & \multicolumn{2}{|c|}{ Study Group } & \multicolumn{2}{c|}{ Control Group } \\
\cline { 2 - 5 } & Number & \% & Number & \% \\
\hline$<15$ & 0 & 0.0 & 18 & 72 \\
\hline $15-30$ & 0 & 0.0 & 7 & 28 \\
\hline$>40$ & 25 & 100.0 & 0 & 0.0 \\
\hline Total & 25 & 100.0 & 25 & 100.0 \\
\hline Mean \pm SD & \multicolumn{2}{|c|}{$43.40 \pm 3.74$} & \multicolumn{2}{c|}{$14.03 \pm 3.45$} \\
\hline
\end{tabular}

Table 5. Percentage \% Area Reduction in Two Groups of Patients

Study group had better wound contraction of Mean \pm SD $43.40 \pm 3.74$ as compared to control group, the mean wound contraction was Mean \pm SD $14.03 \pm 3.45$. these were found to be statistically significant $\mathrm{P}<0.001^{* *}$, significant, on Student $\mathrm{t}$ test

\begin{tabular}{|c|c|c|c|c|}
\hline \multirow{2}{*}{$\begin{array}{l}\text { Weeks for Complete } \\
\text { Healing }\end{array}$} & \multicolumn{2}{|c|}{ Study Group } & \multicolumn{2}{|c|}{ Control Group } \\
\hline & Number & $\%$ & Number & $\%$ \\
\hline 1 week & 0 & 0.0 & 0 & 0.0 \\
\hline 2 weeks & 7 & 28 & 0 & 0.0 \\
\hline 3 weeks & 18 & 72 & 0 & 0.0 \\
\hline 4 weeks & 0 & 0.0 & 1 & 4 \\
\hline 5 weeks & 0 & 0.0 & 17 & 68 \\
\hline 6 weeks & 0 & 0.0 & 7 & 28 \\
\hline Total & 25 & 100.0 & 25 & 100.0 \\
\hline Mean \pm SD & \multicolumn{2}{|c|}{$2.74 \pm 0.45$} & \multicolumn{2}{|c|}{$5.22 \pm 0.52$} \\
\hline \multicolumn{5}{|c|}{ Table 6. Weeks for Complete Healing } \\
\hline \multicolumn{5}{|c|}{$\begin{array}{l}\text { The mean of the time taken for the same healing of the ulcers } \\
\text { were } 2.74 \text { weeks in this study group in comparison to } 5.22 \\
\text { weeks seen with the control group. P VALUE was }-0.01\end{array}$} \\
\hline
\end{tabular}

\section{Dressing Technique}

\section{For Conventional Dressing}

The ulcer was cleaned with normal saline and saline soaked gauze piece was kept over the ulcer which was covered with pad and roller bandage. 


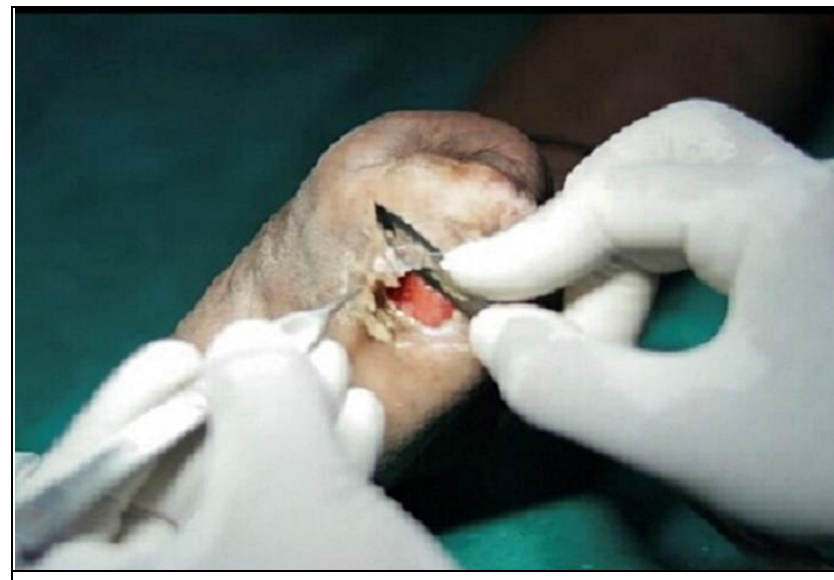

Figure 1. Surgical Debridement and Conventional Dressing

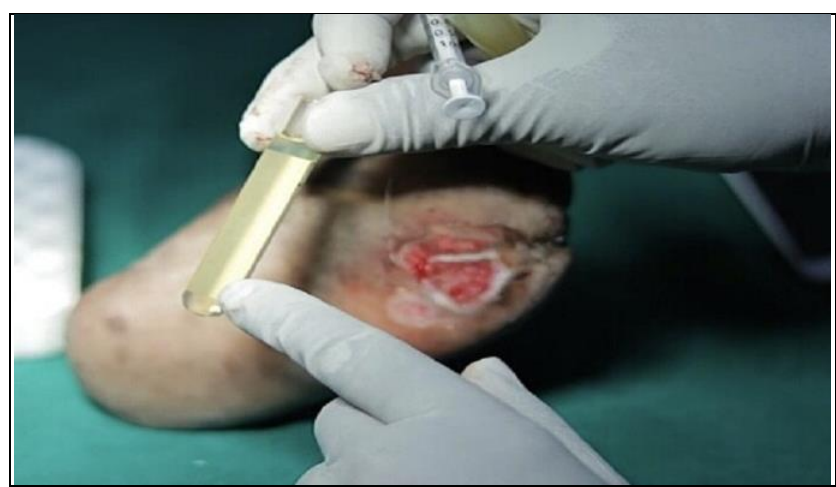

Figure 2. PRP at Lower $1 / 3^{\text {rd }}$ of the Test Tube After Second Spin

\section{For Platelet Rich Plasma Dressing}

The ulcer was cleaned with Normal Saline. Platelet rich plasma was prepared from patients' blood and applied over the wound area twice weekly. After 21 days wounds of both the groups were observed and the wounds were compared based on the following parameters-

- To study healing process of chronic non healing ulcers treated with autologous platelet rich plasma dressing and assesses time taken for development of granulation tissue.

- To apply autologous platelet rich plasma dressings and analyse complications if any.

The dressings were changed as described in both control and study groups for 21 days and appearance of healthy granulation tissue is observed, and the final area is measured on 21 st day by and subjected to statistical analysis.

\section{DISCUSSION}

The management of Chronic non healing ulcers is still a challenge in this advanced medical era because it depends upon multiple factors. The idea of wound dressing to keep it moist and provide the best environment for healing and to prevent from getting infected. The various types of dressings were used to manage chronic wounds.

In Krishna Hospital \& Research Center, Karad. Platelet rich plasma has also been used in various types of surgeries like periodontal, maxillofacial surgery, orthopaedic and trauma. In the past, no adverse reaction or complications have been reported. In this study chronic non healing ulcers management by using platelet rich plasma for wound dressings were selected for the study group and results were compared with conventional dressing.

50 patients participated in this study. Patients with nonhealing ulcers of more than 4 weeks of duration were included in the study, and they were distributed into either study group or control group.

In this study, the chronic lower limb ulcers were more commonly seen in males as compared to females in patients.

The mean age (In years) of the subjects found as 51.77 years in the study group as whereas 50.47 years for the control group.

It was observed, that the subjects from the study group, those who received a wound dressing with Platelet rich Plasma had a better wound contraction $(43.4 \% \pm 3.7)$ as compared to the subjects of the control group, receiving a conventional dressing $(14.03 \% \pm 3.45$ ( $\mathrm{P}$ Value $<0.001)$. Hence from these results it can be deduced that PRP wound dressings are better than conventional dressings with respect to wound contraction in chronic non healing ulcers.

The initial area of ulcers was similar in study and control group with $1328.57 \pm 128.68 \mathrm{~cm}^{2}$ and $1338.08 \pm 131.54 \mathrm{~cm}^{2}$ in the control group. But the final area of the wound after the study was $749.99 \pm 99.97$ in study group and $1149.84 \pm 114.74$ $\mathrm{cm}^{2}$ in control group and the reduction was $579.03 \pm 63.55$ and $214.39 \pm 148.20 \mathrm{~cm}^{2}$. respectively. $(\mathrm{P}<0.001)$

We saw that it took around 2.74 weeks for complete healing of wound dressing done with Platelet rich plasma, while it took 5.22 weeks for the wounds with conventional dressing with $(\mathrm{P}$ value $=0.011)$

In a similar study by Driver et al. ${ }^{5}$ (2006) which included 72 patients showed that Wounds in the PRP group healed after a mean of 42.9 days (SD 18.3) vs. 47.4 days (SD 22.0) in the control group.

Mcaleer et al.6 (2006) used autologous PRP in healing of chronic lower extremity wound in a case study of a 57-yearold man with type 2 diabetes the complete closure of the ulcer was achieved by the fourth week of treatment with PRP.

In a pilot study by $0^{\prime}$ Connell et al. ${ }^{7}$ (2008) the treatment of chronic lower-extremity ulcers with autologous plateletrich fibrin matrix membrane (PRFM), the venous lowerextremity ulcers healed in 7.1 weeks (median six weeks) following an average of two applications of PRFM per patient

Kakudo et al. ${ }^{8}$ treated five cases of intractable skin ulcer with autologous PRP, among which three ulcers healed completely within 4 weeks and epithelization of wound occurred within 6.6 weeks on average.

Still there is no standard method of preparation of PRP in literature. According to Marx, the device must use a double centrifugation technique. Regardless of the rate of centrifugation, the time of centrifugation, a single spin cannot adequately concentrate platelets, because the red blood cells will interfere with their fine separation

Several studies have been conducted on the use of PRP for the treatment of non-healing ulcers and the results have been promising, however, currently, there is a paucity of critical scientific data regarding the beneficial effects of PRP in clinical procedures. 
The present study is conducted on 50 patients to compare the efficacy of platelet rich plasma versus conventional dressing in chronic non-healing ulcers in Krishna Hospital \& Research Center, Karad.

Patients were divided into two groups of 25 patients each and detailed history was taken, and relevant investigations were done to rule out any focus of infection. All the 50 patients were assessed based on many factors e.g. size of ulcer, site of ulcer, culture sensitivity from the ulcer, medical problem like Diabetes Mellitus.

We found that there was significant improvement in ulcer size in group treated with platelet rich plasma. There were no complications seen in either of the group. Lower limbs were the most common site of occurrence of ulcer in the study.

\section{CONCLUSION}

1. PRP showed faster and better healing rates among the study group.

2. Ulcer area reduction and percentage reduction of ulcer size was better in PRP group.

3. Formation of granulation tissue over the ulcer is better and early with PRP group.

4. There were no adverse effects or reactions seen with use of PRP.

Chronic wounds/ non-healing ulcers are a growing socioeconomic problem all over the world. All the conventional treatments relating to chronic wound healing/ulcer is time consuming and expensive. Platelet rich plasma dressing might prove to be the first line remedy for the same and should be promoted as it is safe and costeffective.

\section{REFERENCES}

[1] Sakata J, Sasaki S, Handa K, et al. A retrospective, longitudinal study to evaluate healing of lower extremity wounds in patients with diabetes mellitus and ischemia using standard protocols of care and platelet-rich plasma gel in a Japanese wound care program. Ostomy Wound Manage 2012;58(4):36-49.

[2] Nurden AT, Nurden P, Sanchez M, et al. Platelets and wound healing. Front Biosci 2008;13:3532-48.

[3] Marx RE. Platelet-rich plasma (PRP): What is PRP and what is not PRP? Implant Dent 2001;10(4):225-8.

[4] Sclafani AP. Applications of platelet-rich fibrin matrix in facial plastic surgery. Facial Plast Surg 2009;25(4):270-6.

[5] Driver VR, Hanft J, Fylling CP, et al. A prospective, randomized, controlled trial of autologous platelet rich plasma gel for the treatment of diabetic foot ulcers. Ostomy Wound Manage 2006;52(6):68-70, 72, 74 passim.

[6] McAleer JP, Sharma S, Kaplan EM, et al. Use of autologous platelet concentrate in a nonhealing lower extremity wound. Advances in Skin \& Wound Care 2006;19(7):354-63.

[7] O'Connell SM, Impeduglia $\mathrm{T}$, Hessler $\mathrm{K}$, et al. Autologous platelet-rich fibrin matrix as cell therapy in the healing of chronic lower-extremity ulcers. Wound Repair Regen 2008;16(6):749-56.

[8] Kakudo N, Kushida S, Ogura T, et al. The use of autologous platelet-rich plasma in the treatment of intractable skin ulcer: A case series. Open Journal of Regenerative Medicine 2012;1(3):29-32. 